\title{
¿Puede haber algo que se llame una política ambiental?
}

Freddy Álvarez*

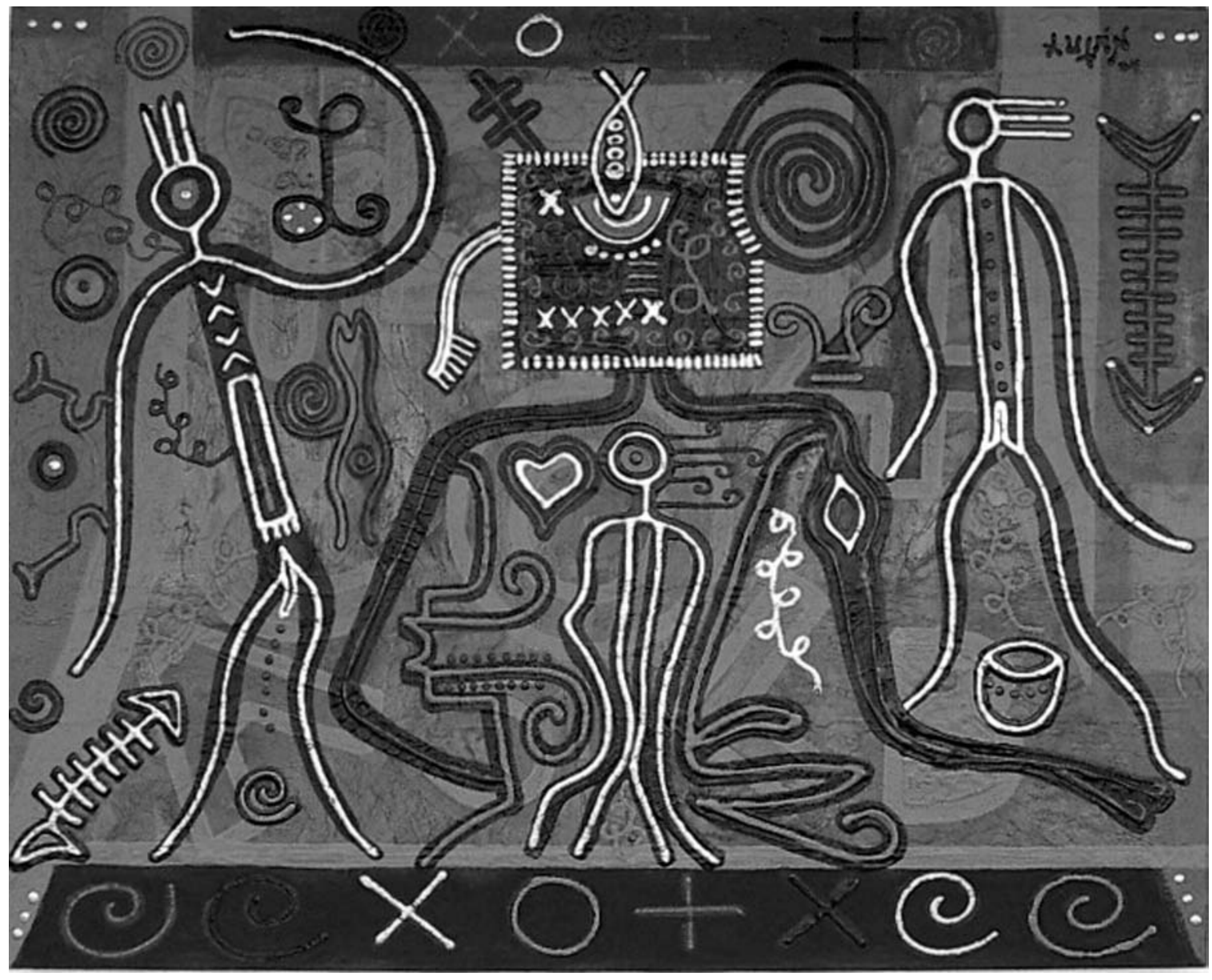

Cosas mías. Técnica mixta sobre lienzo

* Doctor en filosofía por la Sorbona (París VIII). Profesor investigador de la Carrera de Comunicación Social de la UPS y autor de artículos y publicaciones varias sobre filosofía, conocimiento y desarrollo. 


\section{La normalidad psicoanalítica del contexto ambientalista: la paranoia de los líderes, la neu- rosis de los desarrollados, la esquizofrenia de las ONG, la hipocresía de la cooperación y la demencia de la maquinaria burócrata}

La pregunta enunciada de esta manera "puede haber", cuestiona no sólo sobre la existencia de algo, pues existen políticas ambientales; no indaga sobre el "hay" ya que la existencia no está en duda; la pregunta versa sobre el poder de la existencia: es saber si puede existir una política ambiental o no. La existencia nace del poder, porque ser es una cuestión de poder ser, el poder no es la causa del ser, pero no hay ser sin poder. Además no es tener poder, es ser a través del poder. En consecuencia, no existe una política ambiental sólo por querer que haya una política ambiental, hay una política ambiental porque el poder quiere una política ambiental, sin embargo, el poder es limitado y limita el "haber" de la política ambiental. El poder es indispensable para la vulnerabilidad de la políti$\mathrm{ca}$, y el poder vulnera el topos de la política. Luego, el "puede haber" una política ambiental se refiere a la probabilidad, no a una certeza, por tal motivo contiene una tonalidad irreverente porque de hecho casi todos los países del mundo, democráticos y no democráticos, tienen políticas ambientalistas, las cuales no se cumplen en la mayoría de los casos. Pero, ¿por qué iniciar con una pregunta de este modo?

Resulta extraño encontrar que los países ricos con el desarrollo más brutal y contaminante para el mundo, y sin ninguna intención en cambiar dicho modelo, están preocupados por el Medio Ambiente mundial, pero desde horizontes locales proteccionistas, pues, sus desechos peligrosos los envían a países pobres. Ellos han mantenido y mantienen prácticas de saqueo inmisericorde de los recursos renovables y no re- novables del tercer mundo con políticas colonialistas y humillantes, y ahora tales países pretenden dictarle al Sur las políticas ambientalistas sin renunciar a imponer un modelo de desarrollo que sigue manteniendo la dicotomía entre superior e inferior beneficiando sus intereses hegemónicos. En efecto, en torno a la gravedad de los fenómenos ambientales circulan una serie de personajes neuróticos que colocan preguntas lógicas y responden con una multiplicidad de respuestas contradictorias y sin sentido.

Es apenas obvio que las políticas ambientalistas venidas del Norte obedecen a criterios de un Estado de Bienestar, es decir, la demanda ambientalista se inscribe dentro de una neurosis planetaria que después de llegar a un nivel de vida cómodo a costa de políticas extractivistas y coloniales fuera de su país, la mejor manera de disfrutar y gozar de sus beneficios es exigiendo demandas ambientales de los otros.

Mientras tanto algunos líderes políticos del Sur, desde procesos de emancipación, radicales, moderados o incipientes, -muchas veces contradictorios- buscan emanciparse por medio de una disyuntiva cotidiana: o explotar recursos para responder a las promesas políticas hechas a sus electores, o dejar intactos los recursos protegiendo la naturaleza; o arrancar las riquezas de la tierra para solucionar los problemas del hambre y dar inicio a procesos de desarrollo autónomo, o buscar solucionar la pobreza sin recurrir al modelo extractivista del Estado que ha sido endosado por gobiernos invasores y últimamente por transnacionales. La necesidad de recursos apremia por las demandas sociales y las condiciones precarias en las que viven las poblaciones. En consecuencia la oposición de movimientos ambientalistas puristas, que ven a la naturaleza separada de las necesidades sociales y económicas intenta ser contrarrestada por una serie de posturas políticas paranoicas que ven el mal en todo tipo de oposición. Así unos y otros dejan intacto el modelo de desarrollo lineal, mecánico, universal y, pretendidamente, neutral. 
De igual manera, muchos de los Ministerios de Ambiente del Sur siguen atados a las agendas de los Organismos Internacionales por lo que sus políticas reales se quedan en pura retórica. El Norte puede darse el lujo de una política ambiental para sí pero no para los otros, pues allí se suelen encontrar sus fábricas y los recursos que requieren para vivir bien. De hecho, los Ministerios de Ambiente son cooptados a sus demandas ya que el mayor financiador proviene de la Cooperación Internacional quien de cualquier modo coloca los temas a ser tratados subyaciendo en su política la incapacidad del Sur para definir su propio destino. Así, la experiencia de la impotencia de la política ambiental es evidenciada no sólo fuera, sino dentro de la burocracia ministerial. De esta manera, se ocupa un lugar de trabajo desde el cual se sabe, después de un corto tiempo, que allí son muy pocas las situaciones que pueden ser transformadas. Dicha conciencia del fracaso acompaña el día a día de un burócrata provocando que el ángel de la redención sea reemplazado por el diablo de la cotidianidad.

La experiencia de la impotencia y la conciencia del fracaso provocan la inacción burocrática, dentro del vértigo, a veces, de acciones sin sentido que se repiten, replican, traslapan, en un medio institucional parcelado, compartimentado y fragmentado. Se hace nada haciendo muchas cosas o respondiendo automáticamente con atención a no salirse de los marcos legales. El no hacer nada sucede en la carrera por demostrar que se hace algo. Así se cubre la impotencia y el fracaso de no poder redimir a través del cambio.

Las políticas del desarrollo y de la econo-

\section{Bajo la lucha por lo ambiental, nos encontramos con una serie de prácticas} no ambientales. La locura de la lucha ambiental no es pura. Nadie es lo que dice ser, ni siquiera las acciones son la revelación del ser. mía no están articuladas con las vulnerables y vulneradas políticas ambientales. La pregunta ambiental es silenciada ante la urgencia decisiva del factor económico y la incuestionable respuesta decimonónica del desarrollo. La política ambiental navega y naufraga constantemente en un medio esquizofrénico en el que las políticas se hacen para cumplir con determinados convenios, pero no para ser tomados seriamente en cuenta a partir de las necesidades ambientales de las poblaciones y de la naturaleza.

La esquizofrenia de la acción ambiental es experimentada con mayor fuerza en algunas de las ONG ambientalistas financiadas con dineros provenientes de las empresas contaminantes. Luego, la lucha por un medio ambiente no es separable de sus problemas no en una línea causal sino en la relación interdependiente, irónica y circular, por lo tanto, la causa del medio ambiente genera defensores y es porque hay defensores que se requiere de un planeta en llamas. Dicha circularidad a veces toma giros sorprendentes y cínicos cuando a veces entendemos que el énfasis está puesto no en el planeta sino en los intereses de las promesas ecológicas.

Por último, nos encontramos con la Cooperación Internacional quien supuestamente apoya las buenas causas de los gobiernos pobres y que al mismo tiempo opera como centros de inteligencia de los países representados. Grandes títulos ambientalistas se colocan en los edificios de representaciones internacionales para justificar de modo indirecto la larga presencia de una política invasora defensora de los intereses de empresas extractivistas extranjeras y naciones "amigas".

Bajo la lucha por lo ambiental, entonces, nos encontramos con una serie de prácticas no ambientales. La locura de la lucha ambiental no es pura. Nadie es lo que dice ser, ni siquiera las acciones son la revelación del ser. Así, la demencia en la causa ecológica tiene sus propias manifestaciones. La neurosis ante la experiencia de los límites del planeta, la paranoia frente a los grupos ecológicos, la conciencia del fracaso desde 
dentro y la esquizofrenia en la que se sostienen sus políticas constituyen la maldita normalidad.

Las razones no son únicamente marxistas, aunque exista la preponderancia del factor económico. Decir que el planeta se destruye porque lo económico está por encima de lo ambiental es decir mucho y no decir nada. El énfasis marxista tiene también connotaciones anti-ambientales porque en la medida que condenamos lo económico colocamos a las causas ambientales en el punto imposible, tanto para los países dependientes como para los países desarrollados. Un punto imposible es aquel donde la nada es la que comienza a hacer. Así los efectos provocados son aquellos que se quisieron evitar.

¿Cuáles son esas otras razones desde una normalidad psicoanalítica que atraviesan las políticas ambientalistas? ¿Por qué una política ambiental es un posible-imposible? ¿Es la realpolítica un marco justo para la política ambiental? Son éstas las preguntas que nos lanzan en nuestra reflexión sobre el poder hacer de las políticas ambientales. Para la reflexión vamos a comenzar por la necesidad de la contextualidad y el problema universal, luego abordaremos el asunto de la realidad, lo imposible y lo ideal, para terminar en el problema de la topia de las políticas ambientales.

\section{El universalismo contextual de la política ambiental y la necesi- dad de pensar las interrelacio- nes del contexto con el mundo}

De todos lados nos llegan mensajes sobre los problemas ambientales locales, nacionales y mundiales. Ahora algo está ocurriendo que antes no pasaba. El carácter inaudito busca reconocimiento en la política internacional, sin mucho éxito en la política nacional. No es más la repetición, algo emerge con un rostro monstruoso y apocalíptico. Sus características son tan letales que no parecen reales. El presagio pierde su condición futurista pues no señala el adveni-

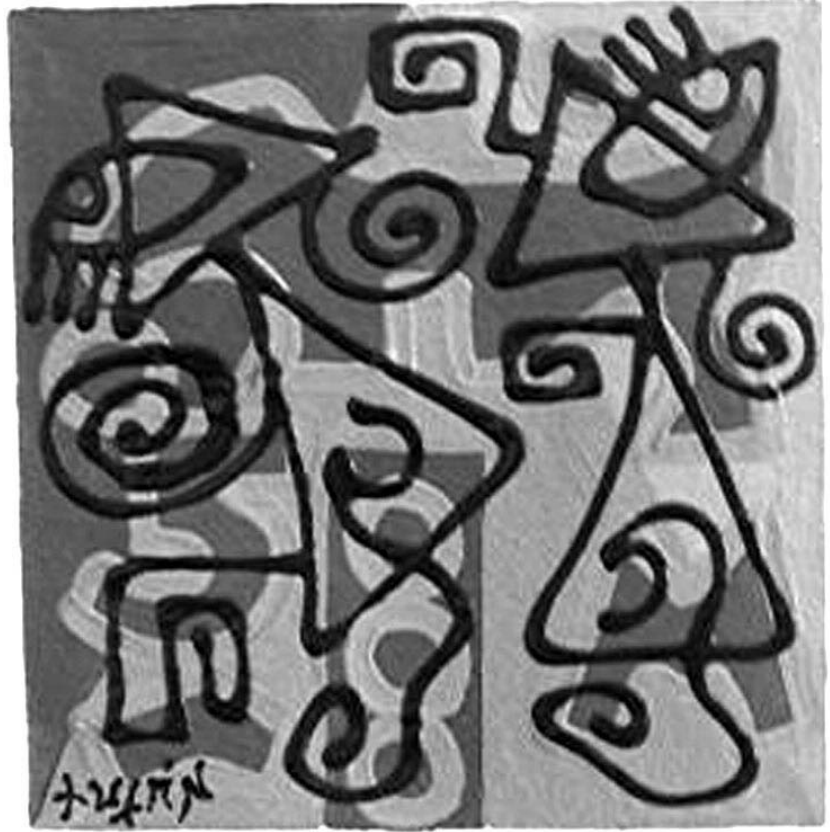

Acrílico sobre papel hecho a mano

miento, por el contrario, ya no ad-viene, está viniendo y no hay manera de detenerlo por su carácter de irreversibilidad. Sin embargo, una figura tan imponente tiene la desventaja de situarnos en una escena mítica e irreal, en cierto sentido, la realidad es tan desbordante y cercana que nos parece imposible que algo así este ocurriendo, es tan real que pasa inmediatamente al ámbito de lo irreal.

El mundo ya no es el mismo ante la catástrofe ecológica. Los desarreglos ambientales nos colocan frente a la comprensión de un mundo diferente: el mundo está interrelacionado y es interdependiente. La casa es de todos y lo que pase en uno de sus cuartos nos afecta a todos por igual. La extrañeza de lo otro, los otros y las otras nos convierte en potenciales asesinos. Dependemos de lo que los otros hagan, así como los otros dependen de lo que nosotros hagamos en esta parte de la casa. Tenemos necesidad de repensar la relación entre nosotros y los otros. Los otros 


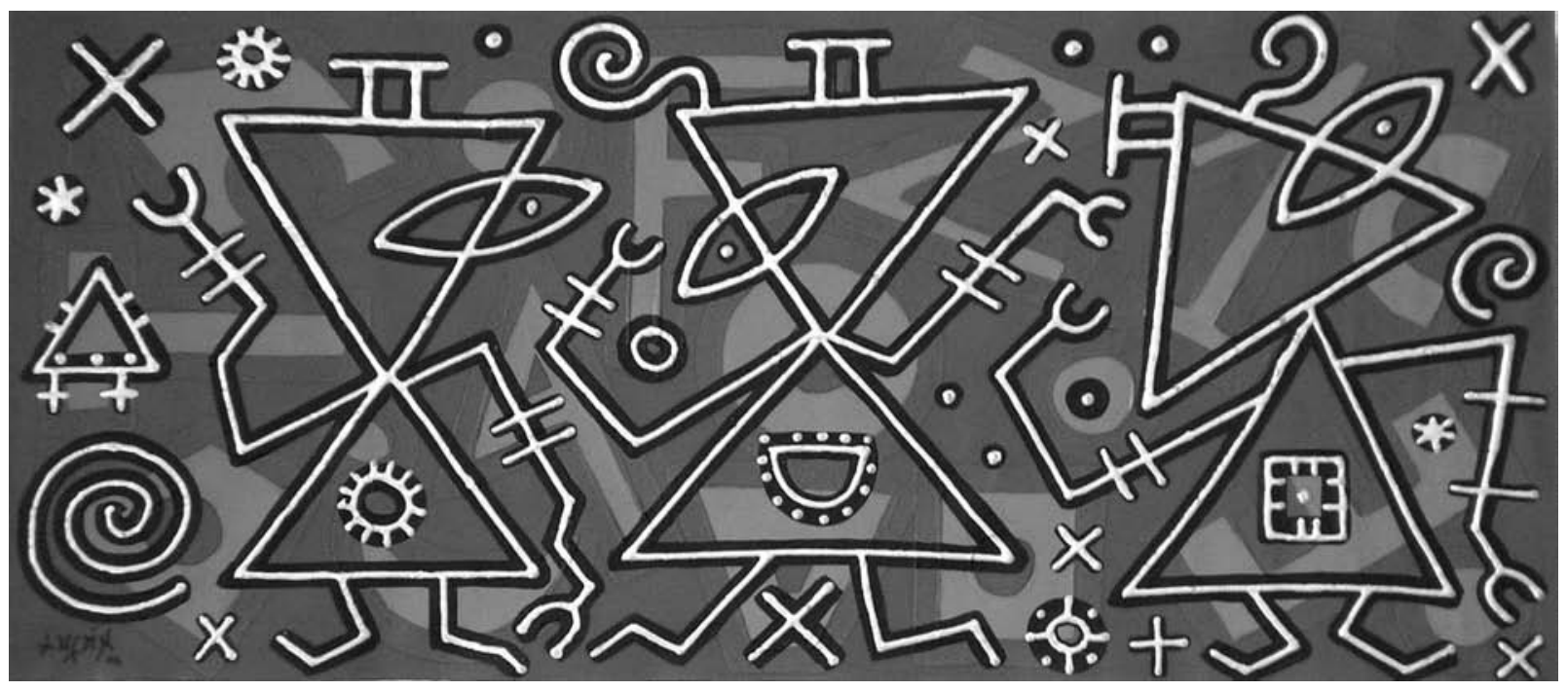

Informalismo panorámico III. Técnica mixta sobre lienzo

habían estado fuera del nosotros. Nosotros éramos en la medida que no éramos los otros. Los otros eran lo que no queríamos ser, sin embargo no había los otros sin nosotros. Nosotros éramos esos otros inconfesos. Ahora sin los otros no hay nosotros y sin nosotros los otros están condenados. La lógica de la acumulación y el racismo está retada en su núcleo. La exclusión y la eliminación eran necesarias para la riqueza como lo han sido para el desarrollo del Norte. El desarreglo del planeta invierte la lógica de la exclusión y la eliminación. Si algo pasa al nosotros, el otro es afectado, porque el duelo ya no es sólo una acción de la voluntad.

La responsabilidad tiene connotaciones mundiales. La responsabilidad nacional en el tema del ambiente nos descubre idiotas. Tenemos tanto derecho a opinar sobre la capa de ozono o la Antártida, como responsabilidad a escuchar las voces sobre la protección de la biodiversidad de la Amazonía. Una responsabilidad parcelada no es más responsabilidad, es inmoral e irresponsable, no es ni siquiera respetable. La responsabilidad es una respuesta a voces con otros, otras y nosotros.
Levinas decía que toda muerte me convierte en culpable. Heidegger pensaba que sólo experimentamos la muerte de otros. Hay un "demasiado tarde" en la experimentación de la propia muerte que contrasta con la muerte antes de tiempo, del inocente. Hablamos de la muerte real de los otros y hablamos de la muerte propia como un hecho irreal. Una distancia tal nos hace caer en trampas. Una de ellas es la experiencia de lo extraño y extranjero. Hay una relación entre lo extraño, lo desconocido, lo lejano y la conciencia en el mundo ambiental. Quizás ya nadie puede decir que no sabía. No podemos evadir la degradación del planeta, y quizás la tragedia sea esa: no la destrucción del planeta, sino la imposible huida. Tenemos mala conciencia desde que nos colocamos frente al espejo para afeitarnos. El mundo se ha convertido en estrecho. El planeta era más solidario que lo imaginado por las grandes utopías, la condición de la biosfera era común y el destino nos unía desde antes.

Pero tras una universalidad ambiental con tintes trágicos se esconden una serie de retos y límites que nos vienen desde la contextualidad. La universalidad es extensiva. Las preocu- 
paciones ambientales se extienden en la conciencia de un alemán, un palestino y un ecuatoriano; sin embargo, el contexto limita y da significado a los sentidos de la interpretación y las respuestas reales. La preocupación es universal pero no la interpretación y mucho menos las respuestas desde lugares específicos. Luego, todos somos o tenemos que ser ecológicos, pero no de la misma manera y con las mismas respuestas e interpretaciones.

Para un alemán la preocupación por el ambiente no está relacionada con los mismos problemas económicos de un palestino o un ecuatoriano. Una respuesta ambiental de un país desarrollado se complejiza en contextos pobres. Las políticas ambientales de Alemania pueden ser ejemplarizantes, mientras ellos inviertan en transnacionales dedicadas a la deforestación de los países pobres. Vivir en situaciones de guerra forcluye las preocupaciones ecológicas para un palestino. La relación con los animales en los países desarrollados es un escándalo con respecto a las políticas internacionales que justifican o se callan frente a la eliminación de los palestinos de parte del Estado de Israel. La pregunta de la vida y la muerte no pasa necesariamente por la pregunta ecológica sino en la medida que la pérdida de la tierra, la negación del agua atenta directamente contra su capacidad de supervivencia. En cierto modo, es más difícil ser ecólogo en Ecuador que en Alemania o Palestina porque los modelos de desarrollo no dejan de ser extractivistas y represivos, no hay interés en investigar en otros modelos y los gobiernos están obligados y son suficientemente corruptos e inmediatistas para no abandonar dicho modelo.

Cuando un modelo ambiental del Norte es colocado en un contexto del Sur se lo hace sin conexiones con lo económico, cultural y social. Fácilmente se pregona una visión de mundo ambiental sin relación con lo social. Se puede apreciar una visión indígena pero de manera exótica. Dichas visiones ecológicas puras no abandonan su carácter colonialista porque son ellos los que enseñan a cuidar el planeta pues los otros son in- capaces mientras siguen sosteniendo relaciones económicas dentro de una ideología neoliberal a ultranza. Los lugares ecológicos valorados sirven para su turismo y un tipo de investigación del expolio al servicio de sus farmacéuticas y de sus patentes.

Pero el panorama de la relación con un universal, aparentemente, siempre impuro enunciado en el campo internacional no implica una renuncia a dar una respuesta desde la cuestión del universal. Tanto la uni-diversidad o la unimultiplicidad van señalando otros caminos en la discusión. Lo cierto es que en un lado y en otro nos encontramos con entrabes. Así, como el marco de un universalismo ha sido impuesto y hace parte de la noción de hegemonía en sentido gramsciano, la contextualidad nos deja frente a algunas trampas. Una de ellas es el aislacionismo o atomismo en el que puede derivar la política, propio de países que actúan desde un nacionalismo a ultranza.

Se ha creído que lo universal es válido y lo contextual es de consumo local. Sin embargo, tenemos elementos contextuales con una enorme capacidad de convertirse en universales y, universales que pierden su carácter dentro de contextos mucho más significativos y diversos. La noción de "Buen Vivir" y "los Derechos de la Naturaleza" de la Nueva Constitución Ecuatoriana se constituyen en patrimonios planetarios. La noción de vida de la Biosfera tiene una carga científica válida pero inaccesible, sin mayores connotaciones culturales, sociales, pero sí económicas. La noción de "vivir bien" del Estado de Bienestar del siglo XIX no corresponde con el "Buen Vivir" del mundo indígena de los Andes. El "vivir bien" del mundo occidental sigue prevaleciendo y tiene una carga importante en la aspiración del desarrollo. El "vivir bien" desconoce las consecuencias éticas, sociales, culturales y económicas. Situar el "Buen Vivir" en la discusión mundial es un asunto de una importancia indiscutible. Pero no todo lo contextual tiene necesidad de ser reconocido universalmente más allá del derecho de la vida a ser construida den- 
No podemos pensar lo ambiental de manera aislada y fragmentada. El contextualismo no es ruptura, es advertir los lazos intercontextuales y mundiales en su espacio y tiempo.

tro de un contexto. Así, la discusión sobre la degradación de la biosfera no es sólo un asunto de reducción de la emisión de gases, es un imperativo a transformar los modos de vida, de producción, de ser, de pensar, de estética y de soñarnos a nosotros mismos. De igual manera, los derechos de la naturaleza son una extensión de la vida a otros sistemas que han dependido del paradigma antropocéntrico. No reconocer los derechos de la naturaleza no es sólo pasar por encima de ella, es pasar por encima de las poblaciones que dependen de ella. Los derechos pertenecen a los individuos y las poblaciones, pero éstos no son posibles sin que la naturaleza no tenga sus propios derechos. Por consiguiente la contextualidad no es aquello que se arrincona en lo local y lo universal no es lo condenado por su condición tensionante con lo local.

La contextualidad es ilusa si no intenta ver más allá de sí misma. En cierto modo, una política ambiental atrapada en los nacionalismos tiene una fuerte dosis de cinismo. No cuidamos la naturaleza por ser ambientalistas, por el contrario el nacionalismo sigue defendiendo un modelo de desarrollo extractivista y contiene en sí los elementos antinacionalistas de la colonialidad. Es decir, el nacionalismo lleva en sí aquello de lo que se intenta separar. Romper con el provincialismo de la política es uno de los desafíos de la política ambiental, porque los hechos de afuera tienen la capacidad de afectarnos adentro, y depende de lo que hagamos aquí con el Medio Ambiente, que afectamos a otros y a otras fuera de nuestro territorio. Cerrarnos a entornos más amplios es propio de un embrutecimiento ilustrado. En consecuencia, aunque la política am- biental tiene que ser redactada en contextos muy específicos, ella no puede ser ajena a la occidentalización del mundo, la internacionalización de la guerra y la crisis económica mundial. Una política ambiental de lo contrario confiesa su presencia correcta en un mundo político interesado en que no vaya más allá, por eso no puede ser ajena a la lucha contra la occidentalización del mundo.

Luchar contra la occidentalización es colocar en las mesas de reflexión de la política ambiental los procesos de mundialización de tipo demográfico, económico, técnico e ideológico que interfieren de manera tumultuosa y conflictiva. Debido a tales flujos, la política ambientalista tiene que ser dinámica. La fidelidad del contextualismo implica estar abiertos a reflexionar sobre el mundo y sus procesos. Los procesos económicos están siendo afectados permanentemente y en la medida que respondamos de manera justa y adecuada a ellos podemos innovar políticas ambientalistas reales, y a la inversa, porque respetamos a la naturaleza y sus derechos podemos pensar en una economía sustentable. Porque nos importa la naturaleza tenemos que buscar respuestas reales desde el desarrollo sustentable, porque hay desarrollo no podemos dejar de lado la pregunta por la naturaleza y el medio ambiente. No podemos ofrecer una solución ambiental sin pensar en nuevas soluciones en los ámbitos sociales, económicos e incluso culturales.

Tenemos que apuntar en política ambiental a una universalidad sin imposiciones pero firme, construida en el diálogo y el desacuerdo que reconozca al mismo tiempo la complementariedad y el antagonismo de la unidad y la multiplicidad. Es un craso error separar el análisis y las respuestas a la crisis de los alimentos, de las fuentes de energía, de la economía de lo ambiental. No podemos pensar lo ambiental de manera aislada y fragmentada. El contextualismo no es ruptura, es advertir los lazos intercontextuales y mundiales en su espacio y tiempo.

La universalidad del contextualismo nos conduce hacia una política ambiental de las interrelaciones de hecho, interrelaciones a partir de 
lo que sucede y que escapa a todo control porque acontece por azar, hacia lo que se quiere, pues las interrelaciones suceden por todas partes, por egoísmo, violaciones, por deseo y algunas mínimas porque son planificadas.

Por último, una política ambiental que junte el contexto con lo universal sabe que las interrelaciones son múltiples, que sus causas son múltiples y que los efectos son más imprevisibles que previsibles. La interdependencia del mundo nos obliga a hacer otro tipo de política ambiental sin caer en una unidad romántica, pues las mismas leyes que nos unen, nos separan, nos juntan y nos dividen; nos igualan y desigualan. Por tal motivo, la reflexión sobre lo real en la política ambiental se impone.

\section{La disyuntiva de lo real y lo ideal en la construcción de la política ambiental}

¿Qué tan real tiene que ser la política ambiental? ¿Qué consecuencias tiene una política ideal en el mundo ambiental? Existe una fuerte tradición en el mundo de la política que se refiere a la real-polítik. Pareciera que nos equivocamos menos cuando partimos de la realidad, así, en política prevalecen las interpretaciones sobre lo dado, por encima de lo que debería suceder porque tiene que ocurrir. Gramsci, Maquiavelo, Weber y Marx coinciden en el rectángulo de lo real. La crueldad y el cinismo son valores indispensables para ingresar en dicho espacio.

Una de las consecuencias de privilegiar la real-polítik es caer en el inmediatismo. La interpretación se hace sobre lo sucedido. El futuro depende de la manera como las piezas vayan siendo movidas en el tablero de ajedrez. La política siempre es nueva, cada día tiene su preocupación, pero dentro de un marco en el que las contradicciones no son sincrónicas sino diacrónicas. Una cosa se dice en un día y puede ser negado en otro porque la situación cambia. Los valores son fruto de la situación y no lo contrario. Así, en un tiempo somos desarrollistas y en otro, ecologistas, todo depende del canto de las sirenas.

La política que menos tiene sentido dentro del ejercicio de la política actual es la política de los ideales. La política ideal traza los caminos por los cuales la realidad debería caminar. Forzamos la realidad para que sea de acuerdo a la manera como nosotros creemos que el mundo debería ser. Así, la real-polítik fácilmente se adapta al mundo de la política renunciado a los ideales del inicio y generando en nosotros un sentimiento de traidores. La ideal-polítik sostiene y agudiza la neurosis al constatar permanentemente que el mundo no es como lo pensamos, que los discursos de izquierda tienen líneas de fuga hacia la derecha, que los amigos pueden ser enemigos y los enemigos pueden ser aliados. Así, aunque la derecha económica no comparta nuestro ideario revolucionario, no por ello deja de ser nuestro aliado cuando se tiene que aprobar un plan de desarrollo de tipo extractivista.

La real-politik es mucho más exigente y se presta a mayores equivocaciones porque el mundo de hoy, no es el mismo de ayer y mañana no será igual al de hoy. Hay una necesidad de estar mirando constantemente el presente, o lo que se denomina comúnmente, "haciendo análisis de coyuntura". En la ideal política, el problema no está en la ideas sino en la realidad. Si el mundo no va bien, es culpa del mundo y no de las ideas. Las ideas las podemos discutir para reemplazar las ideas anteriores. Sin embargo, ¿qué tal real es el mundo de la real-polítik? ¿Y qué tan ideal sea el mundo de la ideal-politik?

La realidad nunca es tan real. No vemos a la realidad de frente, hay una pantalla entre la realidad y nosotros, y lo que vemos depende del lugar en el que nos encontremos, la cultura desde la que lo hagamos, la educación que hayamos recibido, los valores en los que hayamos sido formados. Lo real es un tejido de simbolismos, imaginario y real. Intentar separarlo tiene como consecuencia la pérdida de lo real. Toda mirada a la realidad es una traducción, luego la real-política 
cuando nos quiere decir que ella parte de la realidad mientras que los otros lo hacen desde el ideal. De igual manera, lo ideal no está separado de lo real, como tampoco de lo ideológico. La realidad en ambos casos está puesta en cuestión. La ideal-política sería más honesta porque sólo se atrapa la realidad desde el concepto, situación inaceptable para los obreros de la real-política. Por tal motivo, en muchos casos lo real suele ser más el sueño, la utopía.

Pero la cuestión no es sólo de orden hermenéutico. La realidad nunca es tan real. Dentro de la realidad está lo invisible de la realidad. En todo juicio hay algo que se oculta, toda verdad miente y toda afirmación niega. La realidad tiende a ocultarse en el momento que la señalamos. La problemática ambiental afirma situaciones reales y esconde otras. La objetividad está mediada entre lo que no puede ser dicho sino por otros y atrapada entre lo que se dice y se ve y lo que se oculta, no puede ser visto y es indecible. Cuando Foucault descubre la relación entre saber y poder, devela el ocultamiento de lo no dicho en lo dicho pues el poder está detrás del enunciado, hace parte del ejercicio de la enunciación. La lucha por la objetividad es la lucha por imponer el poder a través de los enunciados. No es raro que en el espacio de los ecologistas sea condenado porque se crítica sus pretendidas posturas objetivas. Es común que los defensores del desarrollo consideran a la ecología como una fábula.

Pero la discusión no es solamente entre lo oculto o no, es también entre lo predecible o no. Morin advierte sobre otro fenómeno llamado los acontecimientos- sphinx los cuales nos muestran la complejidad de la realidad. Un acontencimien-

\section{Los análisis y las acciones simples} rompen el realismo de la realidad. No podemos ser realistas cuando tenemos necesidad de dividir para comprender, de clasificar para ordenar, de explicar para comprender. to-sphinx es aquel que sólo puede ser descifrado en el momento de ser realizado. Si preguntamos a un vulcanólogo sobre la predicción calculada de una determinada erupción volcánica, lo más honesto sería advertir que ese acontecimiento sucederá en el momento que ocurra. La tautología causa risa para un lógico y un científico positivista, sin embargo, en la realidad eso es lo que sucede. ¿Qué significa? Una realidad contiene irrealismos los cuales eran posibles en determinadas circunstancias. Luego, hay realidades que no son comprendidas y, sin embargo, fueron claves en ciertos tiempos. Hay realidades tomadas de manera inadecuada, las cuales se dejaron pasar de largo y retardaron procesos o se convirtieron después en un lastre.

La política en general está acostumbrada a hacer análisis simples. No es raro que la política ambiental quiera ser solamente tratada desde lo ambiental y dentro de lo ambiental los reduccionismos de la política debido a la artesanía de un politólogo, o un abogado, o un biólogo marino, o un ingeniero forestal, llevan a graves consecuencias. Los análisis y las acciones simples rompen el realismo de la realidad. No podemos ser realistas cuando tenemos necesidad de dividir para comprender, de clasificar para ordenar, de explicar para comprender.

Es cierto que debemos ser realistas para hacer una política ambiental, pero sin caer en el inmediatismo que secciona el tiempo o en el idealismo que no está libre de errores. Ninguna teoría va a reflejar la realidad si no es por una creencia metafísica. Debemos saber que la realidad es la idea de realidad y que, por tanto, una política ambiental tiene que ser realista en la medida que hace la apuesta por la realidad posible. Si el realismo es lo inmediato, entonces es ciego, si el realismo es solamente una idea todo lo que este fuera de esa idea es una amenaza para nuestra ideología. El ideal tiene la fuerza para que lo real se calle.

No hay ninguna idea de realidad que no tenga la probabilidad de ser tomada por mitos y por culturas las cuales también están expuestas a 
errores, ilusiones y cegueras. Un mito puede ser más fuerte que los datos de la realidad. El mito tiene la capacidad de desplazar las fuentes históricas y sus causalidades. En consecuencia, ¿hasta dónde parte del discurso ambiental ha sido tomado por mitos indígenas? Las certezas son vulnerables para el mito y la duda suele ser más fuerte que cualquier certeza tal como lo dice el film La Duda de Brian Burns.

Una política ambiental auténtica dialectiza la ideal-politik con la real-politik porque quienes parten de la realidad desconocen incertidumbres, quienes parten de ideas caen en una serie de promesas abstractas. Ni las ideas ni las realidades pueden dejar de lado la discusión sobre lo posible. No todo es posible en un momento determinado. Lo posible tiende a convertirse en imposible. Tener políticas ambientales en el contexto actual es posible, sin embargo, dicha labor se ha convertido en imposible por quienes se enriquecen a costa de un desarrollo lineal, mecánico y brutal para la naturaleza y la salud de las poblaciones y el equilibrio del planeta. Pero así como lo posible se ha convertido en imposible tenemos que hacer la apuesta para que lo imposible se convierta en posible. En consecuencia, la política ambiental tiene la obligación de una mayor audacia. Lo único que nos está prohibido es la superación del segundo principio de la Termodinámica el cual nos recuerda que no hay historia segura, que nada ni nadie es inmortal, que no hay paraíso terrestre y no existe el movimiento perpetuo, todo lo que queda fuera de este principio es posible.

La política es un principio de acción, sin embargo, es probable que la política ambiental nos lleve a la inacción. Si es el caso hay tres consideraciones puestas por Morin para ser tenidas en cuenta: la primera es el efecto perverso, el cual suele ser más importante que el efecto noble. Muchas cosas buenas se pueden hacer, pero si hay algún error, o equivocación, todo es colocado en cuestión por la oposición, e intentará ser enviado al traste, por lo tanto, aunque nos equivoquemos debemos tener la ética para corregir y seguir teniendo persistencia. El segundo principio es la inanidad de la innovación, entre más cambia más tiende a ser la misma cosa, por lo tanto, no debemos celebrar antes de tiempo, ni confundirnos con una política de los resultados. Los resultados pueden aparecer sin que sean indicadores claros del cambio. La política ambiental nos señala la importancia de cambiar modelos de desarrollo y modos de vida que han persistido durante siglos; no es fácil dar un salto pero es un momento para ser audaces. La tercera es la puesta en peligro de las adquisiciones obtenidas. Los grandes saltos en política ambiental colocan en riesgo libertades y seguridades. En muchos momentos este riesgo lo tenemos que afrontar, en otros ser conscientes para que las libertades y seguridades correspondan a una humanidad inter-solidaridades y justa y tener la capacidad de advertir nuevos peligros y nuevas esclavitudes. 


\section{La política utópica entre las topías planetarias}

La crisis planetaria del ambiente impone un formato a la política ambiental el cual nos obliga a responder a la pregunta sobre la barbarie de la civilización en el origen de ella, como lo insinuó Walter Benjamin o en la constante producción de nuevas barbaries en el enfoque freudiano por medio de la ciencia, la técnica y la burocracia. La ciencia con la doble capacidad de solucionar y generar nuevos problemas. La técnica provocando nuevos desafíos de civilización. La burocracia con su funcionamiento obsceno.

¿Qué significa una política ambiental en el horizonte de los límites? La topía de la política se frena frente al futuro teniendo que ir en la búsqueda de una unidad pérdida. Las maletas han quedado en el andén de las promesas. Más allá del olvido del ser está la pregunta por las interrelaciones entre la naturaleza/la especie, la tierra/los individuos y las sociedades/Estado. No podemos seguir edificando una humanidad en oposición a la naturaleza. La tierra no es simplemente el territorio. La especie hace parte del Individuo. El ataque a las sociedades es un ataque a la tierra. La naturaleza tiene que estar al principio y al final.

Si la política del desarrollo fue la promesa del crecimiento infinito e indetenible, los límites emergen por todos los lados, desde la economía, las fuentes de energía, la alimenta- ción, la sostenibilidad del planeta y la capacidad auto-destructora de la civilización. Frente al genio todopoderoso del progreso nos encontramos con el niño a la intemperie del ambientalismo. No todo se puede, tenemos necesidad de girar de lo contrario nos espera un suicidio planetario. La vida precaria de Butler frente a la prepotencia del desarrollo, es aquí donde nos autoreconocemos en la necesidad de una nueva invención que pasa necesariamente por el acto de reinventarnos. De esta manera, la política ambiental se abre contra el modelo de desarrollo impuesto con sus formas destructivas, la esclavitud y la explotación. Quien siga apostándole a este tipo de desarrollo es un genocida. Así, la política ambiental nace en la promesa fallida del paraíso y se construye frente a las puertas del infierno producidas por su discurso.

Las formas de muerte se multiplicaron. La capacidad asesina de la llamada humanidad no se detiene. Una nueva causa de muerte emerge del fondo del Hades provocada por el desarrollo tecno-industrial. Se trata de una muerte en la esfera de la propia vida: la destrucción de la biosfera. Por consiguiente, no podemos seguir afirmando el mundo ordenado de Newton mientras el mundo conocido y domesticado siga generando indefinibles realidades invisibles y peligrosas por su reduccionismo.

El topos de la nueva política nos exige no sólo una relación con un mundo diferente sino también la afirmación del planeta dentro de un universo que con- 
tiene lo desconocido, lo insondable y lo inconcebible. Dentro de este universo surgió la vida, aquí se sitúa nuestro destino, en él encontramos nuestros fantasmas, miedos y voluntades. La vida afirmada en el topos ambiental es interdependiente de la especie y contiene los mismos componentes físico-químicos del planeta.

El límite en el que nace la política ambiental coloca al progreso ya no como una certeza. La evolución no puede ser concebida como un ascenso dada la capacidad destructiva y autodestructiva de la humanidad. Aun los desarrollados no pueden evitar el subdesarrollo mental, psíquico y ético, pues, el desarrollo económico les genera a los desarrollados una miseria humana a manera de un virus sin redención.

La política ambiental implica un reordenamiento de las finalidades terminus. La finalidad no es desarrollarnos, la finalidad es el "Buen Vivir”, y si en esto colabora el desarrollo, bienvenido sea. Pero el desarrollo presente hasta ahora es para "vivir bien" debido al papel que ocupa la economía. El futuro ha sido hipertrofiado por el desarrollo y la economía. Sin embargo, la frustración contagiada por dicho futuro no puede hacernos caer en refugiarnos en un pasado inexistente. Tampoco podemos sacrificar el presente a un pasado autoritario y a un futuro ilusorio. La apuesta por el futuro tiene que estar llena de posibilidades. Ergo, la política ambiental nos lleva a ser vigilantes con las herencias culturales, y comprensivos con las necesidades de recursos.

En el siglo XIX la política tomó a su cargo la economía, a finales del siglo XX la economía ocupa el puesto de la política, pues la política se quedó enredada en el acceso al poder por medio de los partidos. El crecimiento, la estimu- lación y la planificación ha sido parte de la economía. El Estado ha ido haciendo una biopolíti$\mathrm{ca}$, pues su preocupación es la protección, la seguridad, el trabajo, la enfermedad, la vejez, la maternidad, la educación, el tiempo libre. Sin embargo, la política de las grandes ideas se ha ido vaciando para depender de los objetivos económicos: la estabilidad de la moneda, las tasas de crecimiento, el balance del comercio exterior, la productividad, la competitividad, la deuda, etc. La política atrapada en el discurso económico ha caído en un tipo de esclerosis perdiendo la capacidad de comprender los nuevos problemas, de englobar los problemas en enfoques multidimensionales. La política determinada por la economía se disuelve en los problemas administrativos y técnicos. Los burócratas ahora dependen de los econocratas.

En consecuencia, el mayor límite de la política ambiental es la prioridad de la economía sobre cualquier otra dimensión de la política. Después viene la incapacidad de escapar de lo inmediato para construir las políticas a medio término y a largo plazo. La política casi siempre es coyuntural. En lo político se trabaja sobre lo urgente y se deja de lado lo importante.

Además de los tres tiempos existen tres sujetos: las personas, las culturas y las naciones. La política ambiental tiene alcances planetarios los cuales deben ser coherentes con las políticas educativas y sociales. Apuntamos al cambio de las personas sin dejar de lado el diálogo con las cultural y la concreción de políticas internacionales.

Por último, la política ambiental después del fracaso del sueño del desarrollo se enfrenta a un desafío transcendental y es desacelerar la máquina sin control de la tecno-industria. 